\title{
EN MEMORIA DE EUGENIO BULYGIN (1931-2021), A TRAVÉS DE LA DISTANCIA
}

Por lo general, las notas evocativas escritas en ocasión del fallecimiento de una personalidad notable suelen provenir de los seguidores, discípulos o adeptos a las ideas y actuación del homenajeado. No es el caso de la presente nota, ya que a pesar de que compartía con Eugenio Bulygin la misma especialidad filosófica y la consecuente actividad profesional -investigación científica, docencia universitaria, difusión y discusión de ideas, etc.-, nuestros puntos de partida intelectuales, la metodología y las conclusiones a las que arribamos eran en general contrapuestas y, a veces, contradictorias.

A pesar de ello, frente a la desaparición de Eugenio Bulygin, he considerado que, a pesar de esa distancia intelectual, los diversos y relevantes méritos del recientemente desaparecido filósofo ameritan un homenaje y un recuerdo sentido, escrito con admiración a su labor cumplida en el campo de las ideas acerca de la praxis humana y su dimensión jurídica. Seré especialmente breve, no porque no haya mucho que decir en este caso -sería al contrario-, sino porque, por deformación formativa y de personalidad, siempre he tenido tendencia al manuscrito breve y a la exposición lo más escueta posible en mis textos.

Conocí a Eugenio Bulygin en el marco de la creación de la Asociación Argentina de Filosofía del Derecho, que tuvo lugar en la década de 1980, en la ciudad de La Plata, entonces feudo del recordado -aunque un poco extravagante- Juan Carlos Smith. En esa ocasión, me llamó la atención la deferencia, cordialidad y respeto intelectual con que nos trató a los iusnaturalistas presentes, entre los cuales recuerdo especialmente a los doctores Rodolfo Luis Vigo, Julio Raúl Méndez y al meritoriamente recordado Juan Alfredo Casaubon. Esa cordialidad y afecto los tuvo conmigo en todas las ocasiones en las que interactuamos, como cuando participamos de un debate entre el positivismo y el iusnaturalismo jurídicos, con él y Roberto Vernengo representando al iuspositivismo, y Rodolfo Vigo y yo desempeñándonos como iusnaturalistas. El debate fue el más cordial que haya presenciado en mucho tiempo, especialmente por la prudente actitud de Eugenio. En esa oportunidad, estaban presentes, entre 
varios otros, algunos destacados representantes del positivismo jurídico, como Carlos Alchourrón, Martín Diego Farrell y Ricardo Guibourg.

Después de este debate, estuve con él en Brasil, Chile, La Plata y varias veces en Buenos Aires, y siempre me dio muestras de bonhomía y consideración, y pude disfrutar de su conversación amable, irónica, interesante y erudita. Creía además sinceramente en la honestidad intelectual y que la comunidad científica, aún entre estudiosos de diferentes orientaciones, no tenía nada que ver con la política partidista, los sectarismos o las ideologías.

Pero además de su bonhomía y cordialidad, es necesario recordar que, en el caso de Bulygin, se ha estado siempre en presencia de un intelectual que fue objeto de reconocimiento notable, principalmente de carácter internacional, de su actividad académica y científica. Se trató de un reconocimiento merecido, toda vez que su formación científica había sido de especial calidad (Colonia, Bonn, Oxford [con H. L. A. Hart] y varios otros lugares); su producción literaria, prolífica y relevante (15 libros, 137 artículos y 20 traducciones); su participación en centros y asociaciones filosóficas, especialmente destacada y eficiente (fue presidente de la Asociación Mundial de Filosofía Jurídica y Social [IVR] y luego presidente honorario, profesor emérito de la Universidad de Buenos Aires, investigador principal del CONICET, etc.); y recibió numerosos y relevantes premios por su actuación intelectual (Fundación Alexander von Humboldt, British Council, Guggenheim Foundation, Fundación Konex, Premio Alexander von Humboldt, Doctorado Honoris Causa por la Universidad de Alicante, etc.).

En lo que hace a su producción intelectual, es preciso destacar el valor y la especial relevancia que ha tenido su libro Normative Systems, escrito en colaboración con Carlos Alchourrón, que marcó un hito importante en el análisis de los sistemas normativos en la filosofía jurídica del siglo XX y ha sido probablemente el libro más traducido, comentado y estudiado de entre los producidos por autores argentinos, el menos en filosofía del derecho.

Pero lo que -me parece- más vale la pena destacar ahora es el carácter y las cualidades de su producción filosófica. En efecto, más allá del carácter discutible de alguna de las tesis por él defendidas, Bulygin siempre se destacó como un pensador riguroso, que no solo estudió minuciosamente la lógica, sino que también la aplicaba al tratamiento de las cuestiones filosófico-prácticas que abordaba, tales como las referidas a los sistemas normativos, la verdad (o no verdad) de las proposiciones normativas, la indeterminación en el derecho, el positivismo jurídico y tantas más. Siempre fue lo que puede llamarse un intelectual sólido y serio, que intentaba comprobar escrupulosamente el razonamiento y 
las conclusiones a las que arribaba y explicarlas luego de modo claro y preciso. Todo esto fue el resultado de su adhesión a la corriente analítica de la filosofía contemporánea, centrada en la precisión del lenguaje, el rigor de las inferencias y la circunscripción de los problemas a estudiar.

Ahora bien, ¿cuál era el supuesto raigal de la filosofía de Bulygin, el que lo separaba de otras corrientes de pensamiento, en general de inspiración clásica? Tengo para mí que ese supuesto o hipótesis básica consistía en su adhesión a la perspectiva moderna y tardo-moderna de la filosofía, según la cual no resulta posible un conocimiento racional y veritativo de las realidades prácticas, en especial ético-prácticas o morales. Para esta concepción, cuyo origen más decisivo está en el pensamiento de Hobbes ("el nombre de tiranía no significa ni más ni menos que el de soberanía”), los juicios de valor resultan inadmisibles en las consideraciones filosóficas y científicas acerca del hombre y su conducta (política, jurídica o individual). En otras palabras, la ciencia y la filosofía estarían destinadas exclusivamente a la conquista de la naturaleza -como decía Leo Strauss en On Tyranny- y al logro de una mayor precisión del lenguaje y del razonamiento. Por el contrario, para quienes seguimos la "tradición central del pensamiento de occidente" (Isaiah Berlin), ese escepticismo y reduccionismo acerca de los valores humanos y éticos no puede conducir a nada bueno, y sería conveniente iniciar una tarea de revalorización y amplificación de la razón práctico-moral de modo tal que incluya por derecho propio las consideraciones y valoraciones acerca del bien humano en todas sus dimensiones, especialmente las jurídicas y políticas, tal como resulta necesario en temas como la justicia, las virtudes morales y los derechos humanos.

Pero a pesar de esa -y otras diferencias menores-, creo que corresponde en justicia rendirle un homenaje de amistad y admiración a quien hizo de su vida un culto al estudio y la investigación rigurosos, la promoción de la vida académica y la amistad universitaria. Todo eso sin concesiones demagógicas o sectarias, y guardando siempre una admirable coherencia de pensamiento y doctrina. Por eso, desde el otro lado del río de los saberes, vaya para Eugenio Bulygin un saludo lleno de tristeza por su partida, una despedida afectuosa y un recuerdo imborrable de consideración intelectual.

\section{Carlos I. Massini-Correas}

Universidad de Mendoza. Universidad Austral

carlos.massini@um.edu.ar 
